\title{
Emotional determinants of life-space through GPS and ecological momentary assessment in schizophrenia: What gets people out of the house?
}

\author{
Emma M. Parrish a , Colin A. Depp ${ }^{\text {b,c,* }}{ }^{\text {, Raeanne C. Moore }}{ }^{\mathrm{b}}$, Philip D. Harvey ${ }^{\mathrm{d}, \mathrm{e}}$, Tanya Mikhael ${ }^{\mathrm{f}}$, Jason Holden ${ }^{\mathrm{b}}$, \\ Joel Swendsen ${ }^{g}$, Eric Granholm b,c \\ a San Diego State University/University of California San Diego Joint Doctoral Program in Clinical Psychology, San Diego, CA, United States of America \\ ${ }^{\mathrm{b}}$ University of California San Diego Department of Psychiatry, San Diego, CA, United States of America \\ c Veterans Affairs San Diego Healthcare System, San Diego, CA, United States of America \\ ${ }^{\mathrm{d}}$ University of Miami Miller School of Medicine, Miami, FL, United States of America \\ e Research Service Miami VA Medical Center, Miami, FL, United States of America \\ ${ }^{\mathrm{f}}$ Johns Hopkins University School of Nursing, Baltimore, MD, United States of America \\ ${ }^{g}$ National Center for Scientific Research, University of Bordeaux, EPHE PSL Research University, France
}

\section{A R T I C L E I N F O}

\section{Article history:}

Received 25 April 2020

Received in revised form 2 October 2020

Accepted 3 October 2020

Available online $\mathrm{xxxx}$

\section{Keywords:}

Serious mental illness

Anxiety

Avoidance

Motivation

Remote assessment

Functioning

\begin{abstract}
A B S T R A C T
Background: Previous research employing global positioning satellite (GPS) data and ecological momentary assessment (EMA) has shown a smaller life-space (distance traveled from home) was associated with poorer community functioning and more severe negative symptoms in people with schizophrenia. Momentary emotional experiences may influence how much time is spent outside of the home. We evaluated the associations between emotional experiences in relation to life-space among people with schizophrenia compared to healthy controls (HCs).

Methods: 105 participants with schizophrenia and 76 HCs completed in-lab assessments of symptoms, cognition, and functioning. Participants completed EMA assessments of location and emotions seven times daily for seven days at stratified random intervals. GPS coordinates were collected $24 \mathrm{~h}$ a day over the 7-day study period. Analyses were performed at the momentary, day, and full week level using mixed effects models and Spearman correlations.

Results: For HCs, greater happiness was associated with greater concurrent distance traveled away from home as measured by GPS. For participants with schizophrenia, greater anxiety was associated with greater distance traveled away from home and being outside of the home. Less happiness, but not anxiety, was also associated with greater negative symptoms, especially outside the home.

Discussion: These findings suggest diminished positive emotion is associated with the experience of leaving the home in schizophrenia, but also suggest that anxiety may contribute to avoidance of out of home mobility. Interventions targeting both positive emotions and social anxiety may improve social functioning, and life-space may provide a useful outcome for functional rehabilitation interventions in schizophrenia.
\end{abstract}

(C) 2020 Published by Elsevier B.V.

\section{Introduction}

Ecological momentary assessment (EMA) can administer frequently-repeated assessments of real-world experiences using mobile devices, and it has been evaluated in individuals with schizophrenia as a tool to evaluate functioning (Edwards et al., 2018; Granholm et al., 2013; Granholm et al., 2020; Moran et al., 2018). EMA provides simultaneous information on behaviors (e.g., activities), their contexts

* Corresponding author at: University of California San Diego Department of Psychiatry, San Diego, CA, United States of America.

E-mail address: cdepp@ucsd.edu (C.A. Depp). (e.g., time spent at home) and subjective experiences (e.g., emotions). Life-space, an established construct in the disability and aging literature, is a construct that can be dynamically assessed with EMA location reports and GPS sensors (Fillekes et al., 2019). Life-space refers to the physical space emanating from one's home in which one moves around (Fillekes et al., 2019). In our recent report employing EMA and GPS (Depp et al., 2019), people with schizophrenia spent substantially more time at home and traveled shorter distances over a week-long period than did people without a diagnosis of schizophrenia. Another recent study provided psychometric evidence for the use of GPS as a marker of negative symptoms and functional outcome (Raugh et al., 2020). However, little is known about the moment-to-moment or 
day-to-day determinants of life-space in schizophrenia, including emotions, which may have potential as functional rehabilitation targets.

There are a number of static and fluctuating variables that determine life-space in the aging literature: cognition, finances, psychosocial determinants, physical ability, and the built environment (Webber et al., 2010). Studies have shown reduced life-space in older adults is related to poorer cognition (De Silva et al., 2019; Poranen-Clark et al., 2018) and greater severity of depressive symptoms (Jansen et al., 2017). In addition to the aging literature, GPS data such as time spent at home has been associated with greater social anxiety in undergraduates (Boukhechba et al., 2018). One of the few studies to examine this construct in schizophrenia established the feasibility of using GPS as a measure of life-space (Difrancesco et al., 2016), and its use in conjunction with other digital markers (e.g., number of calls placed) may be used as a behavioral marker to predict relapse in people with this disorder (Barnett et al., 2018). More recently, the joint use of EMA and GPS demonstrated that greater time at home and less distance traveled were associated with poorer clinician-rated indicators of community functioning and with more severe negative symptoms, especially diminished motivation (Depp et al., 2019).

Although life-space has been evaluated as a variable in association with in-lab measures, the dynamic influences of emotions on mobility as a motivated behavior has yet to be explored in persons with schizophrenia. Contemporary models of motivation in schizophrenia typically posit that low motivation is linked to deficits in reward systems (NajasGarcia et al., 2018), in particular reward learning (Reinen et al., 2014; Strauss et al., 2013), effort-based decision making (Barch et al., 2014; Green et al., 2015), or diminished capacity to anticipate pleasurable experiences (Gard et al., 2007; Horan et al., 2006). Anticipatory pleasure, or the ability to look forward to pleasurable activities, is diminished in schizophrenia, whereas consummatory pleasure, or the ability to enjoy activities in the moment, is relatively intact (Da Silva et al., 2017; Gard et al., 2007; Green et al., 2012; Horan et al., 2006). As leaving the home is a potentially motivated behavior, we would assume that it would be concurrently associated with positive emotion for healthy controls (HCs), whereas the opposite would be true for people with schizophrenia.

A review of social motivation by Fulford et al. (2018) also highlighted the role of anxious avoidance as components of deficits in motivated social behavior. For example, negative emotional experiences associated with stigma and social rejection may lead people with schizophrenia to distance themselves socially (Green et al., 2017). There is evidence that levels of anxious avoidance in non-affective psychosis are similar to those found in agoraphobia (Freeman et al., 2019), and social avoidance is associated with worsened social functioning (Harvey et al., 2019a, 2019b; Strassnig et al., 2018). Anxiety symptoms and comorbid disorders are common in first episode psychosis and schizophrenia (Achim et al., 2009; Wilson et al., 2019), with social anxiety being one of the most common (Pallanti et al., 2013). Extending this literature of social motivation to a related concept, life-space, it may therefore be expected that individuals with schizophrenia, but not HCs, would experience greater negative emotions such as anxiety as a function of greater life-space. It may also be expected that individuals with schizophrenia, but hot HCs, would experience greater anxiety before leaving the home.

In this case-controlled study, we evaluated the associations between dynamic positive and negative emotional experiences in daily life using both EMA and GPS life-space measures. We hypothesized that greater positive emotions would be contemporaneously associated with greater life-space and time spent outside the home in healthy controls and to a greater extent than in participants with schizophrenia, and that greater life-space and time spent outside the home would be contemporaneously associated with greater anxiety in participants with schizophrenia than HCs. We also examined the directionality of these associations using lagged models, and hypothesized that HCs would have more positive affect when outside of the home and transitioning out of the home, whereas participants with schizophrenia would have more negative affect in these same transitions.

\section{Method}

\subsection{Participants}

The full study protocol has been previously described (Granholm et al., 2020). Briefly, participants were included if they: 1) met criteria for schizophrenia or schizoaffective disorder using the Structured Clinical Interview for DSM-5 (First et al., 2015), or for healthy controls had no current or past mood, anxiety, or psychotic disorders; 2) were aged 18 to $65 ; 3$ ) were fluent in English; and 4) were able to provide informed consent. Participants from both groups were excluded if they had a history of head trauma with loss of consciousness longer than $15 \mathrm{~min}$, a seizure disorder, cerebrovascular accident or dementia, or a current diagnosis of substance dependence that met DSM-5 criteria in the past year. Participants were also excluded if they did not complete laboratory assessments or had vision or hearing deficits that would interfere with the assessments.

\subsection{Procedures}

Participants first completed in-lab assessments, and were then provided a Samsung Android OS smartphone. EMA surveys on this smartphone began the following day, administered seven times a day for seven days using Samplex software. These surveys were given at stratified random intervals in 1.5-hour windows from 9 am to $9 \mathrm{pm}$. Participants were given 15 min to respond after they received an EMA signal, and were paid $\$ 1$ for every survey they completed. GPS coordinates were collected every $5 \mathrm{~min}, 24 \mathrm{~h}$ a day, over seven days using a GPS logger app. After a week of sampling, participants returned to the lab, were paid, and returned the smartphone.

\subsection{In-lab measures}

Cognition was assessed using the MATRICS Consensus Cognitive Battery (MCCB; Nuechterlein et al., 2008). The positive symptom subscale of the Expanded Brief Psychiatric Rating Scale (BPRS; Lukoff et al., 1986) was used to measure positive symptoms. Negative symptoms were measured by the Clinical Assessment Interview for Negative Symptoms (CAINS; Kring et al., 2013).

\subsection{EMA surveys}

Time at home vs. away from home was assessed by the question, "In the past hour, about how much time did you spend at home?" and gave participants the option to indicate 0 to $60 \mathrm{~min}$ (entire time away from home to entire time at home) in 15 min intervals (Granholm et al., 2020). For this study, we dichotomized time spent at home to indicate whether a person was at home the entire hour prior to the survey or not. We used EMA to determine time at home because GPS data was aggregated by day, prohibiting moment-to-moment analyses. Finally, participants rated how happy, sad, relaxed, and nervous (anxious) they were on Likert scales ranging from one ("not at all") to seven ("extremely"). We calculated aggregate variables that showed on average how happy, sad, relaxed, and anxious participants were feeling, as well as the percent of surveys spent at home. These variables were calculated both at the daily level and also for the overall week of sampling.

\subsection{GPS}

The full GPS protocol is detailed elsewhere (Depp et al., 2019). Briefly, the phone produced seven GPS Exchange Format files, one for each day of the study. Longitude, latitude, and tracking variables were recorded every $5 \mathrm{~min}$, leading to a maximum of 288 samples per day. 
In addition, the file contained a note of the estimated positional error, which indicated the precision of the coordinates. Factors that may have affected GPS accuracy include the positioning of the mobile phone relative to satellites, weather, interfering structures, and the GPS sensor. Due to non-normal distribution of the daily GPS values, median values were computed and used in the analysis. We analyzed GPS using a variable examining daily distance traveled away from home, which incorporated GPS distance data from all signals collected in a day.

\subsection{Statistical analyses}

We performed analyses at three different time resolutions: momentary survey level, day level, and full week level. For momentary EMA data, we used time-lagged mixed effects models, with emotion at any given assessment as a ( $\mathrm{T} 0$ ) predictor of a movement variable combining concurrent (T0) and next survey (T1) time points to create four surveyto-survey movement categories: stayed home, left home, went home, stayed out. In each day and week level analysis, we focused on two primary dependent variables of movement: GPS life-space (distance traveled) and separate, self-reported EMA percentage of surveys spent at home. For day level analyses, we used linear mixed models with a random effect for subject and fixed effects for four emotions (happy, sad, anxious, relaxed) related to GPS distance away from home and percentage of surveys at home. For week-level analyses, we computed a mean rating across the week for each emotion separately for when at home and out of home, and computed correlations between these mean emotion ratings and symptoms. Due to the nature of the EMA data and presence of non-normal distributions for several variables, we employed Spearman correlations for all bivariate associations. For analyses of GPS distance traveled, three participants were excluded as outliers due to traveling $>80$ miles per day $(N=1 \mathrm{HCs}$ and $N=2$ schizophrenia respectively), or 4 standard deviations above the mean. In addition, 15 HCs and 12 people with schizophrenia were excluded because they either did not have 7 days of GPS data or a minimum of 20 EMA samples. This yielded a sample for analysis of GPS distance traveled of $60 \mathrm{HCs}$ and 91 people with schizophrenia. All momentary survey analyses included 76 HCs and 105 people with schizophrenia. We set the $p$-value at 0.05 for all analyses.

\section{Results}

\subsection{Sample characteristics}

Demographic characteristics for the overall sample of 76 HC and 105 people with schizophrenia are presented in Table 1. Controls and people with schizophrenia were well-matched on age, gender, and race. Both samples were predominantly white and male. However, people with schizophrenia had less years of education and were less likely to be employed. HCs reported significantly higher ratings of happiness and relaxation, and people with schizophrenia reported significantly higher ratings of anxiety and sadness. Furthermore, the people with schizophrenia spent a greater percentage of surveys exclusively at home, 62.7\% (SD = 19.6), than HCs, $45.0 \%($ SD $=25.2)$. HCs also traveled more miles away per day (Median $=18.9, \mathrm{SD}=14.8$ ) than people with schizophrenia (Median $=7.6, \mathrm{SD}=8.6 ; t(149)=5.97, p<.001$ ).

The sub-sample of participants for day and week level analyses (60 $\mathrm{HC}$ and 91 people with schizophrenia) did not differ substantially on most demographic variables. The full HC sample was older than the subset (mean age $51.2(\mathrm{SD}=10.9)$ vs. $41.5(\mathrm{SD}=12.8), t(74)=-3.07$, $p=.003)$. The full HC sample was also less happy (5.5 (SD $=0.9)$ vs. 4.9 (SD = 1.0), $t(74)=-2.06, p=.043)$ and less relaxed $(5.5(\mathrm{SD}=$ $1.0)$ vs. $4.6(\mathrm{SD}=1.2), t(74)=-2.87, p=.005)$ than the HC subset. There were no further differences between the two HC samples. There were no statistically significant differences between the full and subset samples for the schizophrenia group.
Table 1

Demographic and clinical characteristics.

\begin{tabular}{|c|c|c|c|c|}
\hline \multicolumn{5}{|l|}{ Characteristic } \\
\hline & $\begin{array}{l}\mathrm{HCs} \\
(n=76)\end{array}$ & $\begin{array}{l}\text { People with } \\
\text { schizophrenia } \\
(n=105)^{\mathrm{a}}\end{array}$ & $\operatorname{tor} X^{2}$ & $\mathrm{p}$ \\
\hline Age (M (SD), range) & $\begin{array}{l}49.2 \\
(11.9), \\
22.2-65.4\end{array}$ & $\begin{array}{l}51.9(9.2) \\
26.4-65.0\end{array}$ & -1.69 & 0.094 \\
\hline Sex (\% female) & $36.8 \%$ & $28.8 \%$ & 1.29 & 0.257 \\
\hline \multicolumn{5}{|l|}{ Race/ethnicity } \\
\hline \% Caucasian & $50.0 \%$ & $37.5 \%$ & 9.8 & 0.135 \\
\hline$\%$ African American & $22.4 \%$ & $41.3 \%$ & & \\
\hline \% Hispanic/Latino & $15.8 \%$ & $11.5 \%$ & & \\
\hline \% Other & $11.8 \%$ & $9.6 \%$ & & \\
\hline Education (M (SD), range) & $\begin{array}{l}14.6 \\
(1.8), \\
12-18\end{array}$ & $\begin{array}{l}13.0(1.9) \\
8-20\end{array}$ & 5.6 & $<0.001^{*}$ \\
\hline \% currently employed & $56.6 \%$ & $16.5 \%$ & 33.3 & $<0.001^{*}$ \\
\hline$\%$ living independently & $93.2 \%$ & $70.9 \%$ & 13.6 & $<0.001^{*}$ \\
\hline \multicolumn{5}{|c|}{ Clinical characteristics (M (SD), range) } \\
\hline Global MCCB T-score ${ }^{\mathrm{b}}$ & - & $\begin{array}{l}38.2(6.3) \\
21.8-53.9\end{array}$ & - & - \\
\hline BPRS positive symptoms & - & $9.3(3.8), 3-19$ & - & - \\
\hline CAINS motivation and pleasure & - & $15.9,6.4,3-32$ & - & - \\
\hline CAINS expression & - & $3.5,3.3,0-15$ & & \\
\hline \multicolumn{5}{|c|}{ EMA average affect for week of sampling (M (SD), range) } \\
\hline Happy & $\begin{array}{l}5.4(1.0) \\
2.6-7.0\end{array}$ & $\begin{array}{l}4.7(1.2) \\
1.4-7.0\end{array}$ & 4.4 & $<0.001^{*}$ \\
\hline Sad & $\begin{array}{l}1.6(0.7) \\
1.0-4.3\end{array}$ & $\begin{array}{l}2.6(1.3) \\
1.0-6.3\end{array}$ & -6.8 & $<0.001^{*}$ \\
\hline Relaxed & $\begin{array}{l}5.3(1.1) \\
2.0-7.0\end{array}$ & $\begin{array}{l}4.7(1.1) \\
1.4-7.0\end{array}$ & 3.6 & $<0.001^{*}$ \\
\hline Anxious & $\begin{array}{l}1.6(0.7) \\
1.0-4.2\end{array}$ & $\begin{array}{l}2.6(1.3) \\
1.0-7.0\end{array}$ & -6.5 & $<0.001^{*}$ \\
\hline \multicolumn{5}{|l|}{ Time use } \\
\hline $\begin{array}{l}\text { Percent EMA surveys totally at } \\
\text { home (M (SD), range) }\end{array}$ & $\begin{array}{l}45.0 \\
(25.2) \\
0.0-90.9\end{array}$ & $\begin{array}{l}62.7(19.6) \\
13.5-100.0\end{array}$ & -5.13 & $<0.001^{*}$ \\
\hline $\begin{array}{l}\text { Average daily GPS distance away } \\
\text { (miles; median (SD), range) }\end{array}$ & $\begin{array}{l}18.9 \\
(14.8) \\
0-55.9\end{array}$ & $\begin{array}{l}7.6(8.6) \\
0.0-35.4\end{array}$ & 5.97 & $<0.001^{*}$ \\
\hline
\end{tabular}

Note. MCCB = MATRICS Cognitive Consensus Battery: BPRS = Brief Psychiatric Rating Scale; CAINS $=$ Clinical Assessment Interview for Negative Symptoms.

a Demographic information was missing for 1 person with schizophrenia.

b $N=91$.

\subsection{EMA data with lagged home transitions}

Fig. 1 shows movement in and out of the home for people with schizophrenia and HCs. People with schizophrenia stayed home from survey to survey more often than HCs (46.8\% (SD $=25.2)$ of surveys vs. $32.2 \%(S D=24.0)$, respectively, $t(179)=-3.93, p<.001)$, and HCs stayed out more often from survey to survey than people with schizophrenia $(41.9 \%(S D=28.4)$ of surveys vs. $21.8 \%(S D=16.7)$ of surveys, respectively, $t(179)=5.95, p<.001)$. People with schizophrenia also left home more often than HCs $(16.4 \%$ ( $S D=11.6)$ of surveys vs. $13.2 \%$ ( $\mathrm{SD}=7.9$ ), respectively, $t(179)=-2.06, p=.041)$ and returned home more often than HCs $(15.0 \%(\mathrm{SD}=7.2)$ of surveys vs. $12.7 \%$ $(\mathrm{SD}=7.1)$, respectively, $t(179)=-2.13, p=.035)$. Thus, people with schizophrenia made more brief trips to and from home, but stayed home more and went out less than HCs. Among the participants with schizophrenia, people who were not living independently were more likely to spend time at home ( $56.5 \%$ of surveys vs. $42.9 \%$ for those living independently; $t(101)=2.54, p=.013)$. However, though participants not living independently stayed out less, left homeless, and went home less, these differences were not significantly different ( $p$ 's > .056). 


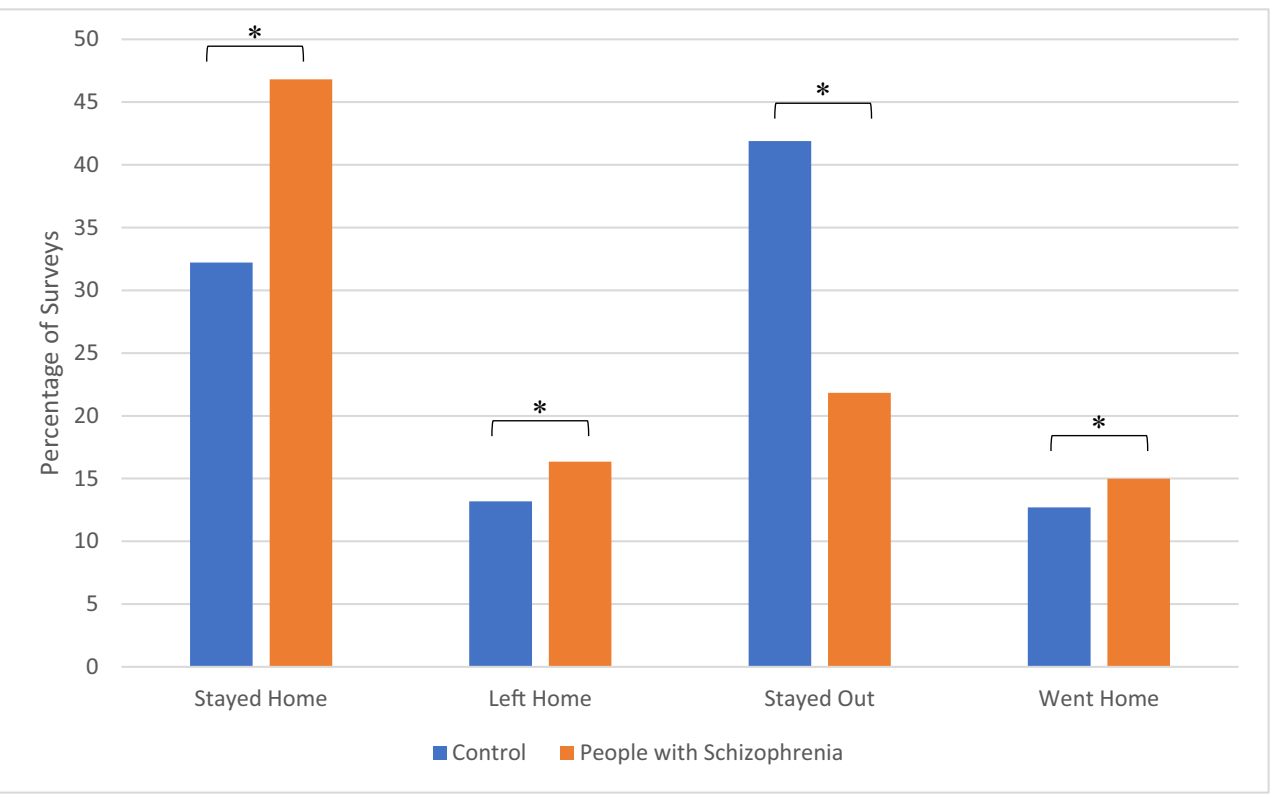

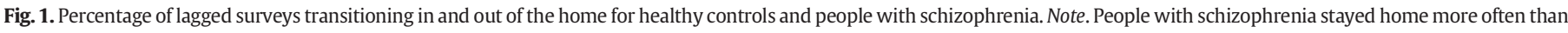

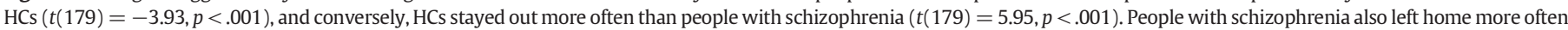

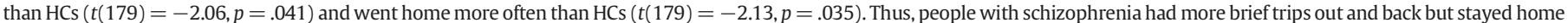
more and out less than HC's.

Fig. 2 illustrates estimated marginal means of the four emotions (happiness, anxious, sadness, and relaxed) preceding the four mobility states (stayed home, stayed out, left home, and went home). Examining pairwise comparisons of the estimated marginal means of happiness preceding the mobility states, there were no significant differences in reported happiness related to subsequent mobility for either group. Pairwise comparisons for anxiousness and sadness for HCs also showed no significant differences between the four mobility states. In contrast, for people with schizophrenia, "stayed home" anxious ratings $(\mathrm{M}=2.2, \mathrm{SE}=0.04)$ were lower than "left home" ( $\mathrm{M}=2.7, \mathrm{SE}=0.07, p<.001)$, "stayed out" $(\mathrm{M}=2.8$, $\mathrm{SE}=0.06, p<.001)$, and "went home" $(\mathrm{M}=2.6, \mathrm{SE}=0.07$, $p<.001$; see Fig. 2). Similarly, for people with this disorder, "stayed home" sadness ratings $(\mathrm{M}=2.4, \mathrm{SE}=0.04)$ were lower than "left home" ( $\mathrm{M}=2.7, \mathrm{SE}=0.07, p<.001)$, "stayed out" $(\mathrm{M}=2.6$, $\mathrm{SE}=0.06, p=.002)$, and "went home" $(\mathrm{M}=2.6, \mathrm{SE}=0.07, p=$ $.007)$ sadness ratings. Pairwise differences in reported relaxed ratings were similar for HCs and people with schizophrenia. For HCs, "stayed out" relaxed ratings $(\mathrm{M}=5.2, \mathrm{SE}=0.05)$ were lower than "stayed home" ( $\mathrm{M}=5.5, \mathrm{SE}=0.05, p<.001)$, "went home" ( $\mathrm{M}=$ $5.4, \mathrm{SE}=0.08, p=.023)$, and "left home" $(\mathrm{M}=5.4, \mathrm{SE}=0.08$, $p=.028)$. For people with schizophrenia, "stayed home" relaxed ratings $(\mathrm{M}=4.8, \mathrm{SE}=0.04)$ were higher than "stayed out" $(\mathrm{M}=4.5$, $\mathrm{SE}=0.06, p<.001)$, "left home" $(\mathrm{M}=4.7, \mathrm{SE}=0.07, p=.013)$, and "went home" ( $\mathrm{M}=4.6, \mathrm{SD}=0.07, p<.001)$. Furthermore, for people with schizophrenia, "stayed out" relaxed ratings $(M=4.5$, $\mathrm{SE}=0.06$ ) were significantly lower than "left home" ratings ( $\mathrm{M}=$ $4.7, \mathrm{SE}=0.07, p=.027$ ).

\subsection{Daily GPS variables related to emotion}

For HCs, greater happiness ratings were associated with more GPS daily distance away from home, $t(184)=2.018, p=.045$, and greater relaxed ratings were associated with less distance away, $t$ $(223)=-2.007, p=.046$. For HCs, there was a trend level association between greater anxiety and greater distance away, $t(342)=$ $1.655, p=.099$. For people with schizophrenia, the only significant association was observed for anxiety, higher ratings being associated with more distance away, $t(380)=2.373, p=.018$. See Table 2 .

\subsection{Emotions, cognition, and symptoms}

Table 3 shows correlations between emotions while at home and away with cognition and symptoms. Global MCCB T-score was not significantly correlated with happiness ( $p$ 's $>.05$ ), but a higher global MCCB T-score was associated with less anxiety at home $(\rho=-0.259$, $p=.013)$, while away $(\rho=-0.243, p=.020)$, and overall $(\rho=$ $-0.270, p=.010$ ). BPRS positive symptoms and the CAINS expression subscale were not correlated with happiness or anxiety at home or out of the home ( $p$ 's $>.05$ ). Greater severity of negative symptoms on the CAINS motivation and pleasure subscale was associated with less happiness at home $(\rho=-0.387, p<.001)$ and while away $(\rho=$ $-0.507, p<.001$ ), but not anxiety. The $\mathrm{Z}$ transformation showed that these correlations were statistically different $(Z=1.725, p=.042)$, such that the correlation between the CAINS motivation and pleasure subscale is stronger with less happiness while away vs. less happiness at home. The correlation between happiness at home/out of the home and the CAINS motivation and pleasure subscale remained significant when controlling for BPRS depression and anxiety (at home: $\rho=$ $-0.407, \mathrm{p}<.001$; away: $\rho=-0.472, \mathrm{p}<.001$ ).

\section{Discussion}

This study evaluated the association between positive and negative emotions and life-space mobility as measured by GPS location data and EMA self-report of location in HCs and people with schizophrenia. As predicted, happiness was positively associated with distance traveled from the home in HCs, but not in schizophrenia. Furthermore, positive emotions in people with schizophrenia, especially outside of the home, was related to diminished motivation and positive experiences. In contrast, anxiety in people with schizophrenia was associated with greater distance traveled, and negative emotions (anxiety and sadness) were associated with moving outside the home in people with schizophrenia, but not in HCs. These results are consistent with reward deficit 


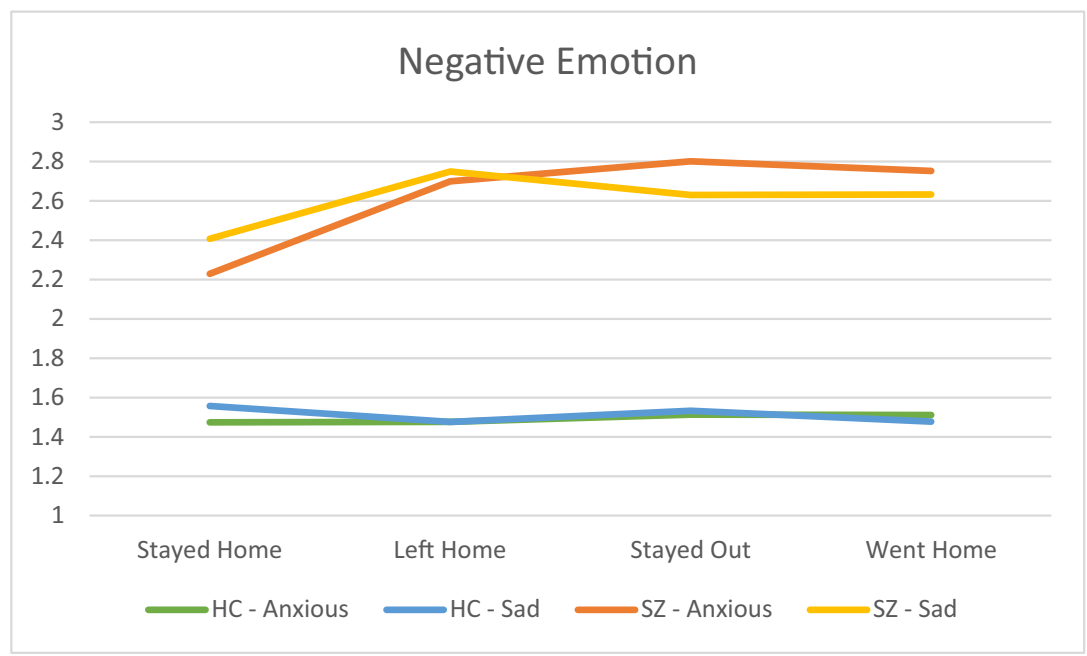

Note. $\mathrm{HC}=$ healthy controls; $\mathrm{SZ}=$ people with schizophrenia

There were no significant negative emotion pairwise comparisons for healthy controls. For people with schizophrenia, "stayed home" anxious ratings were significantly lower than "left home" $(p<.001)$, "stayed out" $(p<.001)$, and "went home" $(p<.00)$. For people with schizophrenia, "stayed home" sadness ratings were lower than "left home" $(p<.001)$, "stayed out" $(p=.002)$, and "went home" $(p=.007)$ sadness ratings.

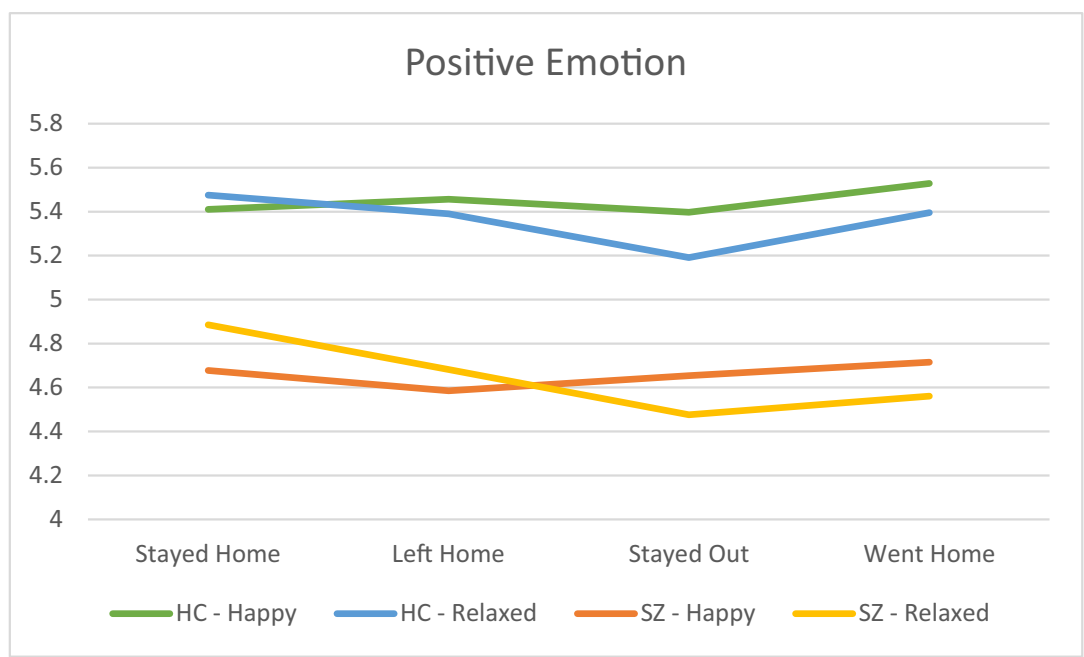

Note. $\mathrm{HC}=$ healthy controls; $\mathrm{SZ}=$ people with schizophrenia

For HCs, "stayed out" relaxed ratings were lower than "stayed home" $(p<.001)$, "went home" $(p=.023)$, and "left home" ( $p=.028)$. For people with schizophrenia, "stayed home" relaxed ratings were higher than "stayed out" $(p<.001)$, "left home" $(p=.013)$, and "went home" $(p<.001)$. Furthermore, for people with schizophrenia, "stayed out" relaxed ratings were significantly lower than "left home" ratings $(p=.027)$. There were no significant differences between the four mobility states related to happiness.

Fig. 2. Emotions when moving in and out of the home.

Table 2

Linear mixed model - daily GPS distance away predicted by same day affect.

\begin{tabular}{lccrc}
\hline Parameter & $\mathrm{B}$ & Std. error & $\mathrm{t}$ & $\mathrm{p}$ \\
\hline \multicolumn{5}{c}{ Controls $(n=60)$} \\
Happy & 5.84 & 2.89 & 2.018 & $0.045^{*}$ \\
Sad & -0.89 & 2.80 & -0.320 & 0.749 \\
Anxious & 4.93 & 2.98 & 1.655 & $0.099^{\dagger}$ \\
Relaxed & -4.91 & 2.45 & -2.007 & $0.046^{*}$ \\
People with schizophrenia $(n=91)$ & & \\
Happy & 0.12 & 1.27 & 0.095 & 0.924 \\
Sad & -0.82 & 1.25 & -0.657 & 0.512 \\
Anxious & 3.21 & 1.35 & 2.373 & $0.018^{*}$ \\
Relaxed & -0.64 & 1.34 & -0.480 & 0.631 \\
\hline
\end{tabular}

* Indicates significant at the $p<.05$ level.

${ }^{\dagger}$ Indicates trend at the $p<.10$ level. models of amotivation and social dysfunction in schizophrenia (Gard et al., 2007; Green et al., 2015; Horan et al., 2006; Najas-Garcia et al., 2018; Reinen et al., 2014; Strauss et al., 2013), but also point to an important role of anxious avoidance and negative emotion in life-space (Fulford et al., 2018; Green et al., 2017).

Positive emotion differed between HCs and people with schizophrenia. Happiness predicted a greater daily distance traveled for HCs but this was not observed for people with schizophrenia, where higher levels of positive emotion, particularly experienced outside of the home, were associated with less severe motivation and pleasure deficits. However, positive emotion was not related to subsequent out of the home mobility in people with schizophrenia. A wide body of literature shows that people with this disorder experience a deficit in anticipatory pleasure (Da Silva et al., 2017; Gard et al., 2007; Green et al., 2012; Horan et al., 2006), which is consistent with our finding that 
Table 3

Spearman correlations between affect in and out of home, cognition, and symptoms in people with schizophrenia $(n=91)$.

\begin{tabular}{|c|c|c|c|c|c|c|}
\hline & $\begin{array}{l}\text { Mean happy at } \\
\text { home }\end{array}$ & $\begin{array}{l}\text { Mean happy out of } \\
\text { home }\end{array}$ & $\begin{array}{l}\text { Overall happy } \\
\text { mean }\end{array}$ & $\begin{array}{l}\text { Mean anxious at } \\
\text { home }\end{array}$ & $\begin{array}{l}\text { Mean anxious out of } \\
\text { home }\end{array}$ & $\begin{array}{l}\text { Overall anxious } \\
\text { mean }\end{array}$ \\
\hline Global MCCB T score & $\begin{array}{l}0.047 \\
(p=.657)\end{array}$ & $\begin{array}{l}0.159 \\
(p=.155)\end{array}$ & $\begin{array}{l}0.098 \\
(p=.358)\end{array}$ & $\begin{array}{l}-0.243^{*} \\
(p=.020)\end{array}$ & $\begin{array}{l}-0.259 * \\
(p=.013)\end{array}$ & $\begin{array}{l}-0.270^{* *} \\
(p=.010)\end{array}$ \\
\hline BPRS positive symptoms & $\begin{array}{l}-0.027 \\
(p=.797)\end{array}$ & $\begin{array}{l}-0.067 \\
(p=.549)\end{array}$ & $\begin{array}{l}-0.041 \\
(p=.701)\end{array}$ & $\begin{array}{l}0.158 \\
(p=.136)\end{array}$ & $\begin{array}{l}0.149 \\
(p=.158)\end{array}$ & $\begin{array}{l}0.163 \\
(p=.123)\end{array}$ \\
\hline BPRS depression/anxiety & $\begin{array}{l}-0.375^{* *} \\
(p<.001)\end{array}$ & $\begin{array}{l}-0.203 \\
(p=.068)\end{array}$ & $\begin{array}{l}-0.378^{* *} \\
(p<.001)\end{array}$ & $\begin{array}{l}0.342^{* *} \\
(p=.001)\end{array}$ & $\begin{array}{l}0.384^{* *} \\
(p<.001)\end{array}$ & $\begin{array}{l}0.377^{* *} \\
(p<.001)\end{array}$ \\
\hline CAINS motivation and pleasure & $\begin{array}{l}-0.387^{* *} \\
(p<.001)\end{array}$ & $\begin{array}{l}-0.507^{* *} \\
(p<.001)\end{array}$ & $\begin{array}{l}-0.422^{* *} \\
(p<.001)\end{array}$ & $\begin{array}{l}0.136 \\
(p=.198)\end{array}$ & $\begin{array}{l}0.155 \\
(p=.141)\end{array}$ & $\begin{array}{l}0.147 \\
(p=.165)\end{array}$ \\
\hline CAINS expression & $\begin{array}{l}-0.048 \\
(p=.651)\end{array}$ & $\begin{array}{l}-0.109 \\
(p=.330)\end{array}$ & $\begin{array}{l}-0.062 \\
(p=.557)\end{array}$ & $\begin{array}{l}0.000 \\
(p=.998)\end{array}$ & $\begin{array}{l}0.009 \\
(p=.936)\end{array}$ & $\begin{array}{l}0.025 \\
(p=.816)\end{array}$ \\
\hline
\end{tabular}

Note. $\mathrm{MCCB}=$ MATRICS Cognitive Consensus Battery: BPRS = Brief Psychiatric Rating Scale; CAINS = Clinical Assessment Interview for Negative Symptoms.

** Correlation is significant at the 0.01 level (2-tailed).

* Correlation is significant at the 0.05 level (2-tailed).

happiness did not predict in/out of home behavior in schizophrenia but did in HCs. Another possibility is that HCs participate in more enjoyable activities outside the home (e.g. productive activities and social interactions; Granholm et al., 2020), potentially attributable to differences in socioeconomic status among the participants with schizophrenia. However, it is important to note that HCs but not people with schizophrenia were less relaxed the further they traveled away from home, which may be related to stress associated with more functional activities (e.g., employment) for HCs.

We found that anxiety was the only significant predictor of lifespace as measured by GPS for people with schizophrenia. On the other hand, anxiety was lower when they stayed home versus transitioned out of the home or stayed out of the home. We speculate that staying at home may be a strategy employed by people with this disorder to avoid anxiety (or sadness), and that less distance traveled from home with accompanying anxiety is a reflective of this avoidance. Avoidance may arise from fear of being stigmatized or learned behavior from negative experiences (Green et al., 2017). While a substantial focus has been placed on reward-related motivation deficits in schizophrenia, anxiety leading to behavioral avoidance may be an important contributor to motivated behavior (Fulford et al., 2018). Interventions that reduce anxious avoidance may be one means to improve life-space and social functioning in this disorder. In addition to highlighting the role of avoidance, this supports the potential use of GPS data as a proxy variable to examine motivated behavior in schizophrenia.

With regard to clinical implications, the results suggest that interventions that target anticipation of pleasurable activities may be effective in improving life-space, as deficits in anticipatory pleasure are often present in schizophrenia (Gard et al., 2007; Horan et al., 2006). Furthermore, previous literature has shown that people with schizophrenia want treatment for anxiety and worry (Freeman et al., 2019). Perhaps exposure-based treatments as well as treatments targeting worry or anxiety may help with experiential avoidance. Locationbased interventions through ecological momentary intervention (EMI) may also be helpful. An app might encourage an individual to savor positive experiences, challenge anxious cognitions, or use breathing exercises to reduce anxiety when outside of the home, and can remind users to anticipate pleasurable experiences and challenge threat cognitions when inside the home and contemplating going out. GPS data can be analyzed in nuanced ways in order to trigger interventions at the right time and place (Fillekes et al., 2019). As with any digital intervention or measurement, it is important to consider user privacy (MartinezPerez et al., 2015).

The present findings should be considered in light of several conceptual and methodological limitations. GPS can be subject to "noise" in the data, including variability in day-to-day traveling distances, inconsistent sampling frequency, and varying accuracy of coordinate locations. The whole sample did not contribute data to GPS analyses as some participants did not have a full 7 days of GPS data or a minimum of 20 GPS samples. This study is also limited by the brief period of sampling and therefore different patterns may emerge over longer periods. In this study, we did not examine exactly where people were and what they are doing at the time of the EMA survey, but rather used in- and out of the home behavior. Furthermore, even though participants reported their locations at T0 and T1, we do not know if they stayed home or left home during the time between those intervals. More detailed contextual analyses may lead to different results.

The clinical sample of this study was outpatients on medications, so individuals who are inpatient or acute outpatients were not included. Therefore, the results of this study may not generalize to individuals with more severe symptoms. Additionally, as the study was funded by the United States Department of Veterans Affairs, the sample was primarily Veterans ( $57.5 \%$ of HCs, $64.4 \%$ of people with schizophrenia), middle aged, and male, so the results may not apply to younger, first episode psychosis clients. Furthermore, the HCs were relatively low functioning with a $43.4 \%$ unemployment rate. It is possible that this may have attenuated some of the differences between in/out of home behavior between HCs and people with schizophrenia.

From a methodological perspective, life-space is a practical measure related to negative symptoms and productive behavior, and sophisticated analyses for examining activities, locations, patterns of movement during the day are possible using GPS data and Geographic Information Systems (GIS) software (Chang, 2016; Difrancesco et al., 2016). These data could be combined with more traditional qualitative research methods in order to more fully understand the subjective emotional correlates of motivated behavior for people with schizophrenia. Future researchers could also incorporate scales of stigma and social rejection to understand the sources and reasons for anxiety among individuals with schizophrenia. In conclusion, we found that the people with schizophrenia have unique emotional predictors of life-space compared to HCs. The findings provide support for both diminished positive experiences associated with leaving the home compared to HCs as well as greater anxiety, and to some extent sadness. The findings suggest that avoidance of anxiety may influence the motivated behavior of leaving the home, which is broadly related to community function.

\section{Contributions}

Below are details of the contributions to this manuscript made by each author:

Emma M. Parrish conducted the literature review, performed data analysis, and took primary responsibility for writing this manuscript.

Dr. Colin A. Depp performed data analysis with Emma Parrish, provided feedback throughout the process, and contributed to drafts of the manuscript. 
Dr. Raeanne C. Moore provided feedback through the process and contributed to drafts of the manuscript.

Dr. Philip D. Harvey provided feedback through the process and contributed to drafts of the manuscript.

Tanya Mikhael contributed to data collection, study design, and drafts of the manuscript.

Dr. Jason Holden was the project manager for the study. He provided feedback throughout the process and contributed to drafts of the manuscript.

Dr. Joel Swendsen provided feedback through the process and contributed to drafts of the manuscript.

Dr. Eric Granholm is the principal investigator of the study. He provided feedback throughout the process and contributed to drafts of the manuscript.

\section{Role of funding source}

This work was supported by VA CSRD Grant 5I01CX000810. The funding source did not play any role in writing this manuscript or in the decision to submit it for publication.

\section{Declaration of competing interest}

Emma M. Parrish, Dr. Colin A. Depp, Tanya Mikhael, Dr. Jason Holden, Dr. Joel Swendsen, and Dr. Eric Granholm have no conflicts of interest to report.

\section{Acknowledgement}

All authors of this manuscript, "Emotional Determinants of Life-space through GPS and Ecological Momentary Assessment in Schizophrenia: What Gets People Out of the House?" have reviewed and approved this version being submitted. This is the authors' original work and it has not been published or submitted for consideration of publication elsewhere.

\section{References}

Achim, A.M., Maziade, M., Raymond, É., Olivier, D., Mérette, C., Roy, M.-A., 2009. How prevalent are anxiety disorders in schizophrenia? A meta-analysis and critical review on a significant association. Schizophr. Bull. 37 (4), 811-821.

Barch, D.M. Treadway, M.T, Schoen, N., 2014. Effort, anhedonia, and function in schizophrenia: reduced effort allocation predicts amotivation and functional impairment. J. Abnorm. Psychol. 123 (2), 387.

Barnett, I., Torous, J., Staples, P., Sandoval, L., Keshavan, M., Onnela, J.-P., 2018. Relapse prediction in schizophrenia through digital phenotyping: a pilot study. Neuropsychopharmacology 43 (8), 1660.

Boukhechba, M., Chow, P., Fua, K., Teachman, B.A., Barnes, L.E., 2018. Predicting social anxiety from global positioning system traces of college students: feasibility study. JMIR Mental Health 5 (3), e10101.

Chang, K.T., 2016. Geographic information system. International Encyclopedia of Geography: People, the Earth, Environment and Technology, pp. 1-10.

Da Silva, S., Saperia, S., Siddiqui, I., Fervaha, G., Agid, O., Daskalakis, Z.J., Ravindran, A., Voineskos, A.N., Zakzanis, K.K., Remington, G., 2017. Investigating consummatory and anticipatory pleasure across motivation deficits in schizophrenia and healthy controls. Psychiatry Res. 254, 112-117.

De Silva, N.A., Gregory, M.A., Venkateshan, S.S., Verschoor, C.P., Kuspinar, A., 2019. Examining the association between life-space mobility and cognitive function in older adults: a systematic review. J. Aging Res. 2019.

Depp, C.A., Bashem, J., Moore, R.C., Holden, J.L., Mikhael, T., Swendsen, J., Harvey, P.D., Granholm, E.L., 2019. GPS mobility as a digital biomarker of negative symptoms in schizophrenia: a case control study. npj Digital Med. 2 (1), 1-7.

Difrancesco, S., Fraccaro, P., Van Der Veer, S.N., Alshoumr, B., Ainsworth, J., Bellazzi, R. Peek, N., 2016. Out-of-home activity recognition from GPS data in schizophrenic patients. 2016 IEEE 29th International Symposium on Computer-Based Medical Systems (CBMS). IEEE, pp. 324-328.

Edwards, C.J., Cella, M., Emsley, R., Tarrier, N., Wykes, T.H., 2018. Exploring the relationship between the anticipation and experience of pleasure in people with schizophrenia: an experience sampling study. Schizophr. Res. 202, 72-79.

Fillekes, M.P. Giannouli, E, Kim, E.-K., Zijlstra, W. Weibel, R, 2019. Towards a comprehensive set of GPS-based indicators reflecting the multidimensional nature of daily mobility for applications in health and aging research. Int. J. Health Geogr. 18 (1), 17.

First, M.B., Williams, J.B.W., Karg, R.S., Spitzer, R.L., 2015. Structured Clinical Interview for DSM-5-Research Version (SCID-5 for DSM-5, Research Version; SCID-5-RV). American Psychiatric Association, Arlington VA.

Freeman, D., Taylor, K.M., Molodynski, A., Waite, F., 2019. Treatable clinical intervention targets for patients with schizophrenia. Schizophr. Res. 211, 44-50.
Fulford, D., Campellone, T., Gard, D.E., 2018. Social motivation in schizophrenia: how research on basic reward processes informs and limits our understanding. Clin. Psychol. Rev. 63, 12-24.

Gard, D.E., Kring, A.M., Gard, M.G., Horan, W.P., Green, M.F., 2007. Anhedonia in schizophrenia: distinctions between anticipatory and consummatory pleasure. Schizophr. Res. 93 (1-3), 253-260.

Granholm, E., Ben-Zeev, D., Fulford, D., Swendsen, J., 2013. Ecological momentary assessment of social functioning in schizophrenia: impact of performance appraisals and affect on social interactions. Schizophr. Res. 145 (1-3), 120-124.

Granholm, E., Holden, J.L., Mikhael, T., Link, P.C., Swendsen, J., Depp, C., Moore, R.C., Harvey, P.D., 2020. What do people with schizophrenia do all day? Ecological momentary assessment of real-world functioning in schizophrenia. Schizophr. Bull. 46 (2), 242-251.

Green, M.F., Hellemann, G., Horan, W.P., Lee, J., Wynn, J.K., 2012. From perception to functional outcome in schizophrenia: modeling the role of ability and motivation. Arch. Gen. Psychiatry 69 (12), 1216-1224.

Green, M.F., Horan, W.P., Barch, D.M., Gold, J.M., 2015. Effort-based decision making: a novel approach for assessing motivation in schizophrenia. Schizophr. Bull. 41 (5), 1035-1044.

Green, M.F., Horan, W.P., Lee, J., McCleery, A., Reddy, L.F., Wynn, J.K., 2017. Social disconnection in schizophrenia and the general community. Schizophr. Bull. 44 (2), 242-249.

Harvey, P.D., Deckler, E., Jarsksog, L.F., Penn, D.L., Pinkham, A.E., 2019a. Predictors of social functioning in patients with higher and lower levels of reduced emotional experience: social cognition, social competence, and symptom severity. Schizophr. Res. 206, 271-276.

Harvey, P.D., Deckler, E., Jones, M.T., Jarskog, L.F., Penn, D.L., Pinkham, A.E., 2019b. Autism symptoms, depression, and active social avoidance in schizophrenia: association with self-reports and informant assessments of everyday functioning. J. Psychiatr. Res. 115, $36-42$.

Horan, W.P., Green, M.F., Kring, A.M., Nuechterlein, K.H., 2006. Does anhedonia in schizophrenia reflect faulty memory for subjectively experienced emotions? J. Abnorm. Psychol. 115 (3), 496.

Jansen, C.-P., Diegelmann, M., Schnabel, E.-L., Wahl, H.-W., Hauer, K., 2017. Life-space and movement behavior in nursing home residents: results of a new sensor-based assessment and associated factors. BMC Geriatr. 17 (1), 36.

Kring, A.M., Gur, R.E., Blanchard, J.J., Horan, W.P., Reise, S.P., 2013. The Clinical Assessment Interview for Negative Symptoms (CAINS): final development and validation. Am. J. Psychiatry 170 (2), 165-172.

Lukoff, D., Nuechterlein, K., Ventura, J., 1986. Manual for the expanded brief psychiatric rating scale. Schizophr. Bull. 12 (4), 594-602.

Martinez-Perez, B., de la Torre-Diez, I., Lopez-Coronado, M., 2015. Privacy and security in mobile health apps: a review and recommendations. J. Med. Syst. 39 (1), 181.

Moran, E.K., Culbreth, A.J., Barch, D.M., 2018. Emotion regulation predicts everyday emotion experience and social function in schizophrenia. Clin. Psychol. Sci. 6 (2), 271-279.

Najas-Garcia, A., Carmona, V.R., Gómez-Benito, J., 2018. Trends in the study of motivation in schizophrenia: a bibliometric analysis of six decades of research (1956-2017). Front. Psychol. 9, 63.

Nuechterlein, K.H., Green, M.F. Kern, R.S, Baade, LE, Barch, D.M. Cohen, J.D., Essock, S, Fenton, W.S., Frese 3rd, F.J., Gold, J.M., Goldberg, T., Heaton, R.K., Keefe, R.S., Kraemer, H., Mesholam-Gately, R., Seidman, L.J., Stover, E., Weinberger, D.R., Young, A.S., Zalcman, S., Marder, S.R., 2008. The MATRICS consensus cognitive battery, part 1: test selection, reliability, and validity. Am. J. Psychiatry 165 (2), 203-213.

Pallanti, S., Cantisani, A., Grassi, G., 2013. Anxiety as a core aspect of schizophrenia. Curr. Psychiatry Rep. 15 (5), 354.

Poranen-Clark, T., von Bonsdorff, M.B., Rantakokko, M., Portegijs, E., Eronen, J., Kauppinen, M., Eriksson, J.G., Rantanen, T., Viljanen, A., 2018. Executive function and life-space mobility in old age. Aging Clin. Exp. Res. 30 (2), 145-151.

Raugh, I.M., James, S.H., Gonzalez, C.M., Chapman, H.C., Cohen, A.S., Kirkpatrick, B., Strauss, G.P., 2020. Geolocation as a digital phenotyping measure of negative symptoms and functional outcome. Schizophr. Bull. (sbaa121).

Reinen, J., Smith, E.E., Insel, C., Kribs, R., Shohamy, D., Wager, T.D., Jarskog, L.F., 2014. Patients with schizophrenia are impaired when learning in the context of pursuing rewards. Schizophr. Res. 152 (1), 309-310.

Strassnig, M., Bowie, C., Pinkham, A.E., Penn, D., Twamley, E.W., Patterson, T.L., Harvey, P.D., 2018. Which levels of cognitive impairments and negative symptoms are related to functional deficits in schizophrenia? J. Psychiatr. Res. 104, 124-129.

Strauss, G.P., Waltz, J.A., Gold, J.M., 2013. A review of reward processing and motivational impairment in schizophrenia. Schizophr. Bull. 40 (Suppl_2), S107-S116.

Webber, S.C., Porter, M.M., Menec, V.H., 2010. Mobility in older adults: a comprehensive framework. The Gerontologist 50 (4), 443-450.

Wilson, R.S., Yung, A.R., Morrison, A.P., 2019. Comorbidity rates of depression and anxiety in first episode psychosis: a systematic review and meta-analysis. Schizophr. Res. 216, 322-329. 